\title{
FUNDAMENTOS CONSTITUCIONAIS DA PROTEÇÃO SOCIAL Continuidades e ruturas
}

\author{
Ana Rita Ferreira \\ Universidade da Beira Interior, Covilhã, Portugal \\ Daniel Carolo \\ Institute of Public Policy Thomas Jefferson-Correia da Serra, Lisboa, Portugal \\ Mariana Trigo Pereira \\ Ministério do Trabalho, da Solidariedade e da Segurança Social, Lisboa, Portugal \\ Pedro Adão e Silva \\ Instituto Universitário de Lisboa (ISCTE-IUL), Lisboa, Portugal
}

Resumo Neste artigo discutimos de que forma a Constituição da República Portuguesa enformou as escolhas políticas presentes na definição do estado social democrático e de que modo os princípios constitucionais se fazem refletir na arquitetura do sistema e se foram alterando ao longo do tempo. Argumentamos que, aquando da transição para a democracia, ao contrário de outras áreas de políticas sociais, a segurança social manteve princípios organizadores anteriores. Contudo, esta resiliência da matriz bismarckiana do sistema português não foi impeditiva da expansão da proteção social portuguesa de acordo com princípios universais e concedeu aos sucessivos governos margem de manobra para definirem políticas programaticamente distintas e

implementarem estratégias reformistas diferenciadas. Concluímos argumentando que, se bem que a Constituição não tenha sido um limite intransponível para a ação política dos executivos, esta tem operado de facto como um ponto de veto, nomeadamente pela forma como o Tribunal Constitucional tem defendido o direito à proteção social, seja numa lógica de seguro social, seja na sua vertente de mínimos sociais.

Palavras-chave: estado social, Constituição, europeização.

Abstract This article discusses the ways in which the Constitution of the Portuguese Republic has embodied to the political choices made during the process of creating and defining a democratic welfare state and how the various constitutional principles are reflected in the architecture of the system and have gradually changed over the years. The authors argue that when Portugal transitioned to democracy, unlike other areas of the country's social policies the social security system retained some of its earlier organising principles. Having said this, this resilience on the part of the Portuguese system's Bismarckian template has not prevented social protection from expanding here in accordance with universal principles, and has given successive governments manoeuvring room in which to define programmatically distinct policies and implement differentiated reformist strategies. The paper concludes by arguing that while the Constitution has not placed an insurmountable limit on governments' political action, it has served as a point of veto, namely by means of the way in which the Constitutional Court has defended the right to social protection, be it in the form of social insurance, be it in the imposition of certain social minima.

Keywords: welfare state, Constitution, Europeanisation.

Résumé Cet article cherche à savoir comment la Constitution portugaise a influencé les choix politiques présents dans la définition de l'État social démocratique et de quelle façon les principes constitutionnels se reflètent dans l'architecture du système et ont changé au fil du temps. L'auteur soutient que lors de l'instauration de la démocratie, contrairement à d'autres domaines de politiques sociales, la sécurité sociale a gardé d'anciens principes d'organisation. Cependant, cette résilience de la matrice bismarckienne du système portugais n'a pas empêché l'expansion de la protection sociale portugaise selon les principes universels et elle a conféré aux gouvernements successifs une marge de manœuvre pour définir des politiques distinctes au plan programmatique et pour mettre en œuvre des stratégies réformistes différenciées. L'article conclut en affirmant que même si la Constitution n'a pas formé une limite infranchissable pour l'action politique des exécutifs, elle a fonctionné en pratique comme un poin de veto, notamment pour la manière dont la Cour constitutionnelle tend à défendre le droit à la protection sociale, aussi bien dans une logique d'assurance sociale que de minima sociaux.

Mots-clés: état social, Constitution, européisation. 
Resumen En este artículo discutimos de qué forma la Constitución de la República Portuguesa conformó las decisiones políticas presentes en la definición del estado social democrático y de qué modo los principios constitucionales se ven reflejados en la arquitectura del sistema y se fueron alterando a lo largo del tiempo. Argumentamos que, en el momento de la transición para la democracia, al contrario de otras áreas de políticas sociales, la seguridad social mantuvo principios organizadores anteriores. Sin embargo, esta resiliencia de la matriz bismarckiana del sistema portugués no impidió la expansión de la protección social portuguesa de acuerdo con principios universales y concedió a los sucesivos gobiernos un margen de maniobra para definir políticas programáticamente distintas e implementaron estrategias reformistas diferenciadas. Concluimos argumentando que, si bien, la Constitución no ha sido un límite intransitable para la acción política de los ejecutivos, esta ha operado de hecho como un punto de veto, a saber, por la forma como el Tribunal

Constitucional ha defendido el derecho a la protección social, sea en una lógica de seguro social, o en su vertiente de mínimos sociales.

Palabras-clave: estado social, Constitución, europeización.

\section{Introdução}

As quatro décadas de democracia traduziram-se numa enorme expansão da cobertura e da generosidade do sistema de proteção social português. A combinação de garantia de novos direitos e novas prestações sociais com o processo de maturação do sistema - fruto de transformações positivas no mercado de trabalho - aumentou a despesa social, com notáveis ganhos de eficácia, qualquer que seja o indicador que consideremos. Se a maturação do sistema é uma característica distintiva da transição democrática, outra, não menos marcante, é a convergência com os parceiros europeus. As políticas de proteção social portuguesas europeizaram-se, quer incorporando princípios organizadores promovidos a partir da Europa social, quer mimetizando soluções inovadoras desenvolvidas por outros estados-membros.

A proteção social foi, por isso, uma área de grande transformação institucional, política e económica que teve amplo impacto social. Com a transição para a democracia, a arquitetura do estado social português alterou-se muito, com implicações materiais de enorme alcance. Contudo, estas alterações tiveram um conjunto de singularidades, desde logo quando se compara com outras áreas sociais (nomeadamente a saúde e a educação).

Enquanto na saúde (com a criação do Serviço Nacional de Saúde) e na educação (com o investimento na escola pública como mecanismo de promoção da igualdade de oportunidades), à democracia correspondeu um movimento de reorientação política e de redesenho institucional do sistema, o mesmo já não é válido, com a mesma extensão, quando pensamos na proteção social - em particular se nos centrarmos na área mais pesada financeiramente, isto é o regime previdencial da segurança social. Este manteve a sua matriz bismarckiana, que, não obstante ter sido criada ainda durante a I. ㄹ República, teve um papel decisivo na definição do código genético do estado corporativo, em particular aquando da tentativa - ainda que largamente frustrada - de modernização do regime, a partir dos anos 60 . 
Apesar da modernização frustrada e da baixíssima eficácia do sistema na resposta à questão social, o legado institucional do estado social corporativo - muito por força de mecanismos de path dependence típicos dos sistemas bismarckianos revelou grande resiliência, tendo passado relativamente incólume pelo processo de rutura política e de democratização. Isto não quer dizer que a democracia não se tenha traduzido num alargamento muito significativo do repertório de direitos e prestações sociais (desde logo com um movimento tendente à universalização da proteção na pobreza e com a extensão muito significativa da cobertura do desemprego) ou, ainda mais relevante, que este alargamento não se tenha traduzido em melhorias das condições de vida dos portugueses - visíveis, por exemplo, na variação positiva dos indicadores de desigualdades e, ainda mais, de incidência da pobreza. A questão é outra: tentar perceber como é que princípios institucionais anteriores à democracia se revelaram persistentes no campo da segurança social, quando noutras áreas sociais o nível de mudança paradigmática foi superior (maxime saúde). Desde logo, a forma como o direito à segurança social, no contexto da CRP, está explicitamente associado à participação anterior no mercado de trabalho, tendo como princípio organizador o seguro social de natureza ocupacional; enquanto o direito à saúde é universal e garantido a todos os cidadãos. Do mesmo modo que importa compreender como é que se processou o equilíbrio entre um sistema previdencial de natureza corporativa com um sistema de solidariedade que foi adquirindo um caráter progressivamente mais social-democrata e beveridgeano (para utilizar as categorias habitualmente mobilizadas na caracterização tipológica dos modelos de proteção social). Aliás, na tensão entre estas duas matrizes tem estado, também, presente uma tensão entre uma visão mais conservadora do sistema (na medida em que é fiel à sua identidade inicial) e uma mais modernizadora que procura introduzir novos princípios, desde logo muito influenciados pela experiência europeia.

Neste texto, procuramos analisar de que forma é que a Constituição da República de 1976 enformou as políticas de proteção social e de que modo os princípios constitucionais se fazem refletir na arquitetura do sistema e se foram alterando ao longo do tempo. Contudo, esta análise não pode ser feita tendo em consideração apenas os princípios enunciados no texto constitucional. Requer, em simultâneo, que se considere a margem de manobra que a CRP deixou aos governos e de que forma estes a utilizaram para redesenhar o sistema, quer quanto aos princípios normativos que foram sendo institucionalizados, quer quanto à partilha de responsabilidades entre estado central, administração local e 3..$^{\circ}$ sector.

O texto está organizado em três partes. Na primeira, discutimos a presença do tema proteção social na Constituição da República e o tipo de implicações programáticas que daí decorrem, bem como a forma como, mais recentemente, a Constituição funcionou, de facto, como um ponto de veto decisivo para circunscrever a margem de manobra do governo, num contexto de austeridade e de restrição de direitos na proteção social. Na segunda, analisamos de que modo os governos utilizaram a margem de manobra constitucional para promover alterações no sistema. Esta análise centrar-se-á nas revisões da Lei de Bases da Segurança Social e na introdução de novas medidas de política que, tendo um caráter inovador, visavam 
também promover a inovação. Na terceira parte, apresentamos alguns indicadores que dão conta da maturação do sistema de proteção social, bem como da sua capacidade de responder aos problemas sociais. Na conclusão enunciamos algumas questões que se colocam à proteção social em Portugal, em particular em torno da sua capacidade para fazer face a desafios futuros, em importante medida moldados por um contexto político, económico e social distinto do dominante aquando do desenho do sistema e da aprovação da Constituição da República.

\section{A proteção social na Constituição da República Portuguesa}

A Constituição Portuguesa determina, desde 1976, que todos os cidadãos "têm direito à segurança social" (art.. 63..$^{\circ}$, n.. 1 ), cabendo "ao estado organizar, coordenar e subsidiar um sistema de segurança social unificado e descentralizado" (art. . 63. , n.o 2, CRP 1976). Esta formulação geral, que subsiste no texto constitucional até hoje, sobrevivendo aos vários processos de revisão constitucional, parece apontar para o princípio da proteção social universal, que historicamente caracteriza a ideologia social-democrata. Ou seja, assim enunciado, o "direito à segurança social" parece configurar-se como incondicional, um direito a ser garantido a todos os cidadãos, em quaisquer circunstâncias, tal como se afirmava para outros direitos sociais, como o direito à saúde ou à educação. Aponta-se, assim, para um modelo de estado social social-democrata, tanto mais que se sublinha caber ao próprio estado organizar os serviços que asseguram esta proteção social aparentemente universal.

No entanto, o mesmo artigo constitucional abre espaço a uma interpretação mais restritiva deste princípio, logo desde a sua primeira versão na história democrática. Com efeito, apesar da formulação universalista inicial, a Constituição estabelece igualmente que "o sistema de segurança social protegerá os cidadãos na doença, velhice, invalidez, viuvez e orfandade, bem como no desemprego e em todas as outras situações de falta ou diminuição de meios de subsistência ou de capacidade para o trabalho" (art.. $63 .^{\circ}$, n.. 4, CRP 1976). Esta explicitação do tipo de proteção social que o estado deveria assegurar mostra que se apontava mais para um modelo de estado social corporativo ou conservador, ou seja, para um sistema de segurança social que visa chegar apenas aos cidadãos trabalhadores (e às famílias dos cidadãos trabalhadores). No fundo, ao referir que o direito à proteção social seria garantido aos cidadãos que se vissem numa das várias situações de risco devido a uma incapacidade para trabalhar, a Constituição parece negar, de alguma forma, a universalidade da proteção social assegurada pelo estado, afirmando antes que o direito à segurança social se destina àqueles que, temporária ou permanentemente, não podem cumprir o dever de trabalhar. Neste sentido, refira-se que a Constituição reforçava esta ideia quando afirmava, num outro artigo, ser dever do estado garantir "o direito a assistência material dos que involuntariamente se encontrem em situação de desemprego" (art. 52. .o alínea a), CRP 1976), ou seja, ao frisar que a proteção social se destinava àqueles que se encontrassem sem trabalho contra a sua vontade.

Assim, ao contrário do que afirmava relativamente ao direito à saúde e à educação, que eram assegurados a todos os cidadãos, a Constituição de 1976 parece 
tornar a garantia deste outro direito social condicional: a segurança social pública será assegurada apenas a quem cumprir (ou a quem tiver cumprido, ou a quem for familiar direto de quem cumpriu) a condição de trabalhar e se vir impedido de a cumprir em algum momento. Isto significa que a segurança social era pensada, segundo o modelo bismarkiano, como um seguro social para aqueles que contribuíam financeiramente para o próprio sistema, por via de descontos sobre os seus salários, e não como um direito incondicional, a ser garantido por via de prestações sociais sem base contributiva.

É, aliás, possível compreender este primado do modelo corporativo de proteção social quando nos focamos num outro aspeto do texto constitucional: aquele que diz respeito à componente redistributiva do sistema de impostos. A Constituição de 1976 afirma que "o sistema fiscal será estruturado por lei, com vista a repartição igualitária da riqueza e dos rendimentos e à satisfação das necessidades financeiras do estado" (art. ${ }^{\circ} 106 .{ }^{\circ}$, n.. 1, CRP 1976), o que, indo ao encontro da ideia social-democrata de necessidade de redistribuir a riqueza de modo a reduzir as desigualdades, revela, simultaneamente, como se entendia que esta função de diminuição do fosso entre os cidadãos mais favorecidos e os mais desfavorecidos cabia ao sistema tributário e não ao sistema de segurança social. Ou seja, ao tornar explícito que a fiscalidade assumirá este objetivo igualitário e ao não afirmar o mesmo para o sistema de segurança social, a Constituição deixa implícito que esta meta igualitária não será de facto o principal fim da proteção social.

Porém, há ainda um outro aspeto que nos permite perceber como o modelo de proteção social concebido na Constituição de 1976 se afastava da ideologia social-democrata tradicional e se aproximava mais do conservadorismo político, nomeadamente tal como reinterpretado pela democracia-cristã de meados do século XX: e este aspeto tem que ver com o facto de o texto constitucional valorizar a existência de organizações privadas de prestação de cuidados sociais. Efetivamente, o mesmo artigo relativo à "segurança social" afirma que "a organização do sistema de segurança social não prejudicará a existência de instituições privadas de solidariedade social não lucrativas" (art. ${ }^{\circ}$ 63, n. ${ }^{\circ}$ 3, CRP 1976), o que indica que o "terceiro setor" era entendido como um ator relevante, a par do estado, no desempenho de funções de segurança social. Esta ideia vai ao encontro da valorização do papel das estruturas sociais intermédias, nomeadamente a igreja, próprio do corporativismo, que leva a considerar que cabe a estas estruturas, e não ao estado, a prestação de cuidados sociais (por exemplo, com idosos, crianças, etc.).

Deste modo, é possível perceber que a Constituição de 1976 estabeleceu um sistema de segurança social mais próximo de um modelo corporativo ou conservador, afastando-se do princípio universalista social-democrata, de matriz beveridgeana. E este quadro não se alterou substancialmente ao longo dos anos nas sucessivas revisões constitucionais (em 1982, 1989, 1992, 1997, 2001, 2004 e 2005).

Com efeito, se é verdade que, a partir de 1982, enquanto diminuía a carga ideológica associada ao período de transição democrática, a Constituição passou a afirmar de forma clara que uma das tarefas fundamentais do estado consistia em procurar desenvolver uma sociedade mais igualitária - "promover o bem-estar e a qualidade de vida do povo, a igualdade real entre os portugueses e a efetivação 
dos direitos económicos, sociais e culturais" (art.ํ⒐, alínea d), CRP 1982) -, o que poderia ser entendido como uma mudança ideológica no sentido de uma visão mais universalista da proteção social, potenciadora de maior igualdade, a verdade é que o restante articulado não sofreu alterações de monta que projetassem essa mudança. Pelo contrário, a revisão constitucional de 1982 veio até especificar que as "instituições particulares de solidariedade social não lucrativas" - cuja existência não seria prejudicada pelos serviços de segurança social públicos - teriam especial incidência na "prossecução dos objetivos" (art.․ 63. . , n.ํㅜ 3, CRP 1982) relacionados, por exemplo, com a criação de redes de assistência materno-infantil, de

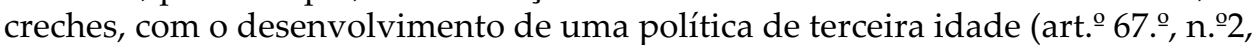
alínea $b$ ), CRP 1982), com estruturas de apoio à infância (art.. 69.․ CRP 1982) à juventude (art.. 70.. , CRP 1982), ou às pessoas portadoras de deficiência (art.. 71. ${ }^{\circ}$, CRP 1982). Ou seja, deste ponto de vista, acentuou-se a importância concedida às associações da sociedade civil no desempenho de funções sociais que, numa visão mais social-democrata, caberiam ao estado. Ficou, pois, mais explícito que o estado não teria a obrigação constitucional de prestar, ele próprio, serviços como creches ou lares da terceira idade, por exemplo, à semelhança do dever que tinha de erguer serviços públicos de saúde e de educação.

Apesar de algumas poucas e ligeiras alterações na redação - por exemplo, aquando da revisão de 1989, a Constituição passou a dispor que era "reconhecido o direito de constituição de instituições particulares de solidariedade social não lucrativas com vista à prossecução dos objetivos de segurança social" (art. ${ }^{\circ}$ 63.. , n.. 3 , CRP 1989) referidos acima, e, a partir da revisão de 1997, passou a afirmar que o estado apoiava a atividade destas instituições (art.. $63 .^{\circ}$, n. ${ }^{\circ}$ 5) - , estas não traduziram mudanças de conteúdo. Após sete revisões constitucionais, a proteção social continua a ser garantida nos mesmos termos em que foi concebida na sua génese: como um sistema de seguro social, válido para trabalhadores e para as suas famílias, em momentos em que estes se encontrem involuntariamente afastados do mercado de trabalho.

De forma idêntica, o artigo relativo ao sistema fiscal - apesar de, a partir de 1989, vir a sofrer alterações que podem permitir uma interpretação bem menos igualitária do que aquela que a versão de 1976 havia instituído - continuava a manter a ideia de que a função redistributiva da riqueza ocorria por via do esquema tributário, pois estipulava: "O sistema fiscal visa a satisfação das necessidades financeiras do estado e outras entidades públicas e uma repartição justa dos rendi-

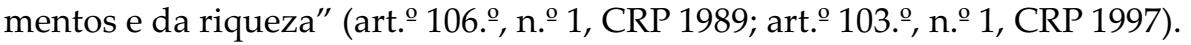

Por tudo isto, é possível perceber que prestações sociais contributivas, como o subsídio de desemprego, ou as pensões de reforma, de invalidez, de sobrevivência, têm, no nosso ordenamento jurídico, uma proteção constitucional clara; é possível até concluir que mesmo a efetivação de uma pensão mínima ou de invalidez, que não se baseasse numa carreira contributiva, estaria constitucionalmente protegida, dado que se afirma, de forma geral, a necessidade de proteger os cidadãos na "velhice"; mas é igualmente possível inferir que prestações sociais não contributivas - como são hoje os casos do rendimento social de inserção ou do complemento solidário para idosos - não gozam do mesmo nível de proteção constitucional. No 
limite, seria inconstitucional pôr fim à existência de um subsídio por desemprego ou a uma pensão de reforma, mas não seria inconstitucional pôr fim ao RSI. Na realidade, o facto de nenhum dos processos de revisão constitucional ter vindo alargar a proteção social ou alterar a natureza corporativa da proteção garantida - de modo a demonstrar vontade de alargar o leque de direitos sociais, estendê-los a todos os cidadãos e assegurar a prestação pública de cuidados sociais - permite-nos fazer esta interpretação.

No entanto, é certo que, em 2002, chamado a pronunciar-se sobre o RSI, o Tribunal Constitucional (TC) considerou que um corte desta prestação seria inconstitucional, dado que violava o "direito a um mínimo de existência condigna inerente ao princípio do respeito pela dignidade da pessoa humana" (Acórdão do TC n. - 509/02). Com efeito, à época, o presidente da República (PR), Jorge Sampaio, requereu ao TC a apreciação da constitucionalidade do artigo 4. ${ }^{\circ}$, n. ${ }^{\circ} 1$, do Decreto da Assembleia da República n.. ${ }^{\circ}$ 18/IX, ${ }^{1}$ uma vez que este propunha que a titularidade do direito ao RSI passasse dos 18 para os 25 anos, o que faria com que cidadãos com menos de 25 anos não pudessem ter acesso a esta prestação social, podendo ficar, por isso, sem qualquer apoio financeiro por parte do estado. No seu requerimento de fiscalização da constitucionalidade, o PR afirmava precisamente que o RSI constituía uma "concretização do direito de todos à segurança social" (idem), tal como estipulava o art. ${ }^{\circ}$ 63. ㅇ da CRP. Assim, a sua questão surgia do facto de considerar que esta prestação social dava "cumprimento às imposições constitucionais" (idem) e que, por isso, o estado não podia retroceder na sua concessão, pois isso significaria uma "restrição do conteúdo dos direitos sociais". O PR ia até mais longe na sua argumentação, considerando que a supressão de uma prestação "de forma arbitrária, discriminatória" iria violar até princípios constitucionalmente consagrados como o princípio da confiança (por se atacar um direito adquirido), o da igualdade (dado que introduzia uma discriminação com base na idade) ou o da universalidade na titularidade e exercício de direitos.

Na sua apreciação, porém, o TC não considerou que a limitação etária pusesse em causa estes princípios, entendendo antes que poria em risco "o princípio do respeito pela dignidade humana", dado que esta implicaria a "garantia a um mínimo de subsistência condigna" (idem). O TC não viu como uma obrigação constitucional do estado a instituição de uma prestação como o RSI para todos os cidadãos, admitindo que "o legislador goza de margem de autonomia necessária para escolher os instrumentos adequados para garantir esse direito" (idem) à subsistência condigna, podendo, por exemplo, considerar que, relativamente aos jovens, "não deveria ser seguida a via do subsídio, mas antes a de outras prestações, pecuniárias ou em espécie, como bolsas de estudo, de estágio ou de formação profissional" (idem). Assim, não existindo, como o TC reconhecia, esses outros instrumentos capazes de garantir a subsistência, a norma punha em causa esse direito ao mínimo da existência condigna. No entanto, se é verdade que o acórdão, ao fazer uso deste

1 Foi, aliás, este decreto que deu origem à lei que transformou o rendimento mínimo garantido em rendimento social de inserção. 
princípio, permite ter uma interpretação mais extensiva dos deveres de proteção social por parte do estado, pois permite-se ir mais longe do que a enunciação constitucional dos direitos sociais, também é igualmente verdade que o mesmo acórdão afirma que há uma "diversidade de meios possíveis" para garantir o "mínimo indispensável" (idem) à existência. Ou seja, se o estado tem a obrigação de garantir um mínimo, o poder político pode decidir qual o instrumento a que recorrerá para isso, "em função das circunstâncias e dos seus critérios políticos próprios" (idem).

Esta decisão parece vir negar aquilo que afirmámos acima relativamente à possibilidade de uma prestação como o RSI dificilmente poder ser considerada passível de proteção constitucional, mas, paradoxalmente, reforça precisamente essa ideia. Senão, vejamos: o TC acorda na ideia de que o estado deve assegurar a todos os cidadãos o mínimo indispensável à sobrevivência, mas não considera que essa garantia tenha que ser obrigatoriamente prestada por via de uma prestação social, nomeadamente desta prestação social em concreto - sendo que o mesmo entendimento dificilmente seria válido a respeito do subsídio de desemprego, da pensão de reforma, ou outra, cuja discriminação constitucional é objetiva. Na verdade, esta decisão não é tão clara que não nos permita pensar que um modelo de estado social liberal estaria conforme a Constituição, ao ser capaz de garantir apenas uma "rede de segurança" mínima a todos os cidadãos (não participantes do mercado de trabalho), mesmo que esta fosse prestada por outras vias (por exemplo, mais caritativas), sem se confundir com um direito social de cidadania. Pelo contrário, ficamos sem respaldo absoluto sobre se seria constitucionalmente possível pôr fim ao RSI, desde que o estado assegurasse um outro mecanismo garante da sobrevivência. E esta interpretação só é possível precisamente porque o texto constitucional nunca afirma de forma taxativa ser obrigação de o estado garantir aos cidadãos que não estejam inseridos no mercado de trabalho uma prestação pecuniária.

\section{A Constituição da República Portuguesa e o programa de ajustamento}

A importância da consagração na Constituição de determinados direitos foi particularmente visível durante os anos de vigência do programa de ajustamento celebrado com a troika, nomeadamente em 2013, aquando da aprovação de um diploma que previa um corte de $10 \%$ do valor das pensões de aposentação, reforma, invalidez e sobrevivência superiores a 600 euros. Com efeito, confrontado na altura com o pedido de fiscalização da constitucionalidade desta medida específica, o TC veio a pronunciar-se pela sua inconstitucionalidade por considerar que ela, cortando objetivamente pensões constitucionalmente garantidas, punha em causa o princípio da confiança que subjaz ao ordenamento constitucional. À época, o PR, Aníbal Cavaco Silva, veio requerer a apreciação das alíneas $a), b$ ), c) e $d$ ) do n. ${ }^{-} 1$ do artigo 7.. do Decreto da Assembleia da República n.. ${ }^{\circ}$ 187/XII, alegando, entre outros argumentos, que este corte afetaria "retrospetivamente as expectativas de continuidade de fruição de um direito social já constituído (a aquisição concreta do direito à segurança social, constante do artigo 63. . da CRP)", o que violava o princípio da confiança, que 
funcionava como um limite estruturante do regime de direitos fundamentais (Acórdão n.. 862/203 do Tribunal Constitucional).

Na sua apreciação, o TC considerou que a matéria "indiscutivelmente se insere no direito da segurança social: diminui-se o valor das pensões de aposentação, reforma, invalidez e sobrevivência, eventualidades que o n. 3 do artigo 63.. da CRP integra na segurança social", pelo que uma alteração do valor destas pensões afetaria, assim, "direitos de caráter social que fazem parte do conjunto de institutos jurídicos que formam a segurança social" (idem). Neste caso, o TC foi efetivamente mais claro na afirmação de que o direito dos cidadãos à segurança social incluía, por imposição constitucional, o dever de o estado pagar estas prestações financeiras específicas. Se é verdade que o órgão fiscalizador considera que "a Constituição não autonomiza expressamente, e nesses termos, um 'direito à pensão', também é certo que nos diz que, "no entanto, o direito à pensão é um dos corolários do direito à segurança social "como um todo'", daí que o próprio TC já por diversas vezes tenha reconhecido "o direito à pensão, nomeadamente, à pensão de velhice, invalidez e viuvez, como um direito constitucionalmente protegido" (idem).

$\mathrm{O}$ facto de ter a força de um direito fundamental inscrito na CRP faz com o TC adote sobre as pensões uma visão diferente daquela que revelou, anos antes, relativamente ao RSI, considerando agora que o direito às pensões teria enraizamento suficiente para dever ser abrangido e protegido pelo princípio constitucional da confiança. Por essa razão, o TC considerou que os cidadãos tinham expectativas "legítimas" e "justificadas", criadas pelo estado, relativamente à continuidade destes benefícios, tendo feito "planos de vida" baseados nesse pressuposto, não podendo a ação do estado pôr em causa essa "estabilidade" sem que haja "razões de interesse público" que justificassem uma ação tão extrema (idem). Ora, mesmo perante os argumentos do governo sobre a necessidade de sustentabilidade do sistema público de pensões, de justiça intergeracional e de convergência do regime de pensões da CGA com o regime geral da segurança social para justificar este diploma legislativo, o TC não considerou possível coartar-se, nesta situação, o "direito adquirido" à pensão por parte daqueles que já eram beneficiários - nomeadamente por estes terem programado a sua vida em função da auferição de um determinado montante de pensão, não podendo reorganizar-se de outra forma por já não estarem inseridos na vida ativa. Por isso, conclui o TC, "a redução das pensões operada através do artigo 7. . do Decreto n. ${ }^{-}$187/XII é uma medida regressiva que mina a confiança legítima que os pensionistas têm na manutenção do montante de pensão que foi fixado com base na legislação vigente à data em que se aposentaram" (idem), tanto mais que "o direito à pensão em pagamento foi sempre salvaguardado, criando o estado expectativas de que os chamados"direitos adquiridos" não seriam afetados" (idem). Neste acórdãoé, aliás, salientada a importância da base contributiva destas pensões na criação destas expetativas justas e sólidas (base que não existe nas prestações não contributivas), o que remete precisamente para a natureza de seguro social associada a este sistema de proteção, pois é-nos dito que "a confiança que os pensionistas depositam no sentido de inalterabilidade das regras que serviram de base ao cálculo da pensão e do valor da pensão que foi fixado no momento da aposentação resulta também da natureza contributiva do sistema previdencial" (idem). 
No fundo, este caso recente mostrou como a Constituição, ao proteger determinados direitos (nomeadamente, a segurança na velhice e na doença), impede a prossecução de políticas que limitam ou eliminam a proteção social necessária à sua efetivação (i.e., as prestações pecuniárias pagas nestas situações). Além disso, os dois casos referidos - o de 2002, relativo ao RSI, e o de 2013, relativo às pensões de aposentação, reforma, invalidez e sobrevivência - vêm mostrar como o TC tem atuado como um garante da força constitucional dos mecanismos de segurança social. No entanto, o que a comparação entre estes dois casos não deixa igualmente de mostrar é o facto de alguns tipos de proteção social assentarem num edifício mais frágil por não estarem claramente enunciados no texto da Constituição. Prestações sociais não contributivas, apesar da sua matriz social-democrata, não estão explicitamente consagradas como direitos fundamentais e, por esse motivo, poderão ser mais facilmente postas em causa do que prestações contributivas, que, pelo contrário, estão claramente vertidas no enunciado constitucional.

\section{0 anos de políticas sociais - reformas no sistema de segurança social}

Na análise do sistema de proteção social português e na sua articulação com os preceitos constitucionais, importa ter presentes as diferentes componentes, designadamente:

i) A configuração/arquitetura do sistema em que, usando a terminologia tradicional, importa distinguir a componente previdencial (seguro/contributivo) da componente da assistência (solidariedade/não contributivo), dadas as diferenças em termos de prestações, mas, sobretudo, nas condições de acesso a essas mesmas prestações, que na prática constituem a materialização dos direitos.

ii) Para além da arquitetura, há também que considerar a evolução da cobertura pessoal (prestações) do sistema, nomeadamente ao nível dos mínimos sociais garantidos, em que se destacou primeiro a pensão social em 1976, depois o alargamento do subsídio de desemprego em 1985 e o RMG em 1996.

iii) Ao nível da evolução da cobertura material (montantes), em que as alterações introduzidas nos últimos anos com os cortes nas pensões e a taxa de contribuição extraordinária de solidariedade (CES) (além dos salários e impostos extraordinários sobre o 13.ำ mês), constituirão porventura o aspeto mais marcante em torno dos pressupostos constitucionais, não obstante em todas as reformas da segurança social $(2000,2002,2007)$ o tema ter estado presente e o legislador ter tido permanentemente preocupação com o respeito integral dos "direitos adquiridos".

iv) Por fim, o 3. . Sector - evolução das parcerias/transferências de competências e recursos na área da educação (pré-escolar) e assistência/cuidados pessoais a grupos vulneráveis (crianças, deficientes, idosos). 


\section{Reformas no sistema de segurança social}

\section{A. Reformas até à Lei de Bases de 1984}

Em termos de política de segurança social, os primeiros anos de transição para a democracia foram marcados pela introdução de medidas elementares como a atribuição do subsídio de Natal nas pensões, logo em 1974; a criação da pensão social para todos aqueles que não estivessem incluídos num dos regimes previdenciais existentes; a decisão política de se reconhecer um esquema mínimo de proteção social [em 1979 com Maria de Lurdes Pintassilgo, no governo dos 100 dias], que sendo logo revogado, ainda assim, em 1980, obrigou à criação do regime não contributivo, abrindo a porta ao reconhecimento genérico do direito à segurança social não dependente da vinculação previdencial (carreira e descontos).

A Lei de Bases de 1984 constituiu o remate do sistema (Mendes, 2005: 117), procurando incorporar as transformações ocorridas numa nova configuração legal, mais do que institucional - pois desse ponto de vista houve, naturalmente, uma continuidade de todos os regimes criados pelo corporativismo (Lucena, 1976, 1982), ainda que subordinados aos princípios democráticos dos direitos sociais. Em suma, a Lei de Bases de 1984 veio integrar os progressos entretanto ocorridos aos quais há ainda que acrescentar a nova legislação do subsídio de desemprego em 1985 (que já existindo estava longe de ser universal) 2 , introduzindo um novo quadro conceptual, sem no entanto criar qualquer rutura no plano institucional.

Em suma, nesta primeira fase que levou uma década (1974-1984), procurou-se harmonizar o quadro legal do sistema de segurança social, em conformidade com a CRP de 1976. Num outro ângulo de análise, note-se que a legislação corporativa vigorou por mais oito anos após aprovação da Constituição o que permite sustentar os elementos de continuidade já apontados em secções anteriores deste artigo.

\section{B. Europeização e inovação: 1986 - 2002}

A par do efeito de universalização/maturação do sistema de segurança social, importa ainda referir o efeito da europeização, decorrente da adesão de Portugal à CEE/UE em 1986 (Guillén, Álvarez e Silva, 2005).

Note-se que a única prestação que se pode considerar nova neste período, ou seja, que previa a resposta a uma eventualidade não coberta anteriormente, é o rendimento social de inserção (RSI), criado em 1996, então com a designação de rendimento mínimo garantido (RMG) - que, apesar do intenso debate ideológico, configurou o reconhecimento do direito de todos os cidadãos a um rendimento de subsistência (Branco, 2001), universalizando assim a cobertura material e pessoal de uma política de garantia de mínimos sociais mas também de direito à inserção social.

2 Em 1981 absorvia apenas 1,7\% da despesa social pública (Costa, 1986). 
Esta fase correspondeu a um período de modernização do sistema de proteção social em que se verificou uma mudança fundamental. A política social passou a ser pensada não apenas ao nível nacional, mas, também, supranacional, e foram acrescentados pressupostos científicos na formulação das próprias políticas e dispositivos de intervenção (Pereirinha e Nunes, 2006). É neste sentido que as especificidades do rápido desenvolvimento do modelo social europeu em países como Portugal (Silva, 2002), com uma combinação não usual de traços de cariz corporativo com outros de cariz universal, permitem advogar a existência de um modelo de estado-providência da Europa do Sul (Ferrera, 1996). Um dos aspetos mais críticos associados aos países da Europa do Sul prende-se com a menor eficácia do seu sistema na diminuição da pobreza. A este respeito, tanto a produção científica sobre o tema como a publicação de indicadores de análise comparada foram decisivos para que os governos tomassem medidas para fazer face a problemas específicos, como foi o caso do plano de erradicação da exploração do trabalho infantil, da criação do RMG em 1996, a pensar nos grupos excluídos do mercado de trabalho, e da preocupação com aumento das pensões mínimas, dada a incidência da pobreza entre os pensionistas (Costa et al., 2008),

Por conseguinte, a este período correspondeu igualmente uma convergência excecional da despesa social com a média dos países europeus (UE-15), ainda que em grande medida tal tenha sido o resultado do processo de maturação do sistema de pensões (Carolo, 2015: 73-78), não obstante a relevância das medidas tomadas no reconhecimento formal do acesso ao rendimento como condição de cidadania, indo assim até além do previsto na CRP 1976.

\section{Maturação/contenção:}

As reformas na austeridade - o caso das pensões (de 2002 em diante)

Tal como vimos a maturação do sistema de pensões, constituiu a principal, ainda que não única, rubrica de convergência com o modelo social europeu em termos de despesa social.

Sendo importante notar que o crescimento da despesa social, sobretudo das pensões, foi um fenómeno que se iniciou logo na década de 1960 (Carolo e Pereirinha, 2010). Assim, para além do forte crescimento da despesa social no período 1960-1975, a um ritmo muito superior ao dos países da então CEE, conforme foi demonstrado noutros estudos [Maia (1984); Costa (1986); Carreira (1996: 470)], e da relevância da reforma da previdência social de 1962 na institucionalização de um regime de segurança social que cobrisse todos os trabalhadores, permitindo assim a inclusão dos trabalhadores rurais entre 1969 e 1973 (Carolo, 2006), a transição para a democracia, para além do já mencionado reconhecimento do direito à segurança social como condição de cidadania com a Constituição de 1976, consagrou, pela nova Lei Orgânica da Segurança Social em 1977, a adoção de um modelo de financiamento por repartição em substituição do anterior regime de capitalização (Mendes, 2005: 116). Importa salientar que este é o regime de financiamento que tem vigorado até ao presente e que, por isso, terá sido 
a principal reforma no sistema. Ainda que em termos práticos não se tenha repercutido em alterações institucionais, esta decisão foi porventura a forma de financiar, juntamente com os excedentes da previdência existentes, a expansão da cobertura material e pessoal do "regime não contributivo".

Contudo, esta fase expansionista, com recurso a um modelo de financiamento mais eficiente, a repartição (também designado por PAYG), cedo sofreu um revés, fruto da necessidade de ajustamento orçamental. Logo no início dos anos 80 , na sequência da crise de 1978 e da intervenção financeira do FMI, ocorreu um período de contenção da despesa na segurança social, com o aumento dos prazos de garantia para as pensões de velhice e a reformulação dos regimes de proteção social dos trabalhadores agrícolas. Por conseguinte, pode considerar-se que mesmo antes da primeira Lei de Bases da Segurança Social de 1984, já haviam sido introduzidos vários cortes e restrições no acesso ao sistema de pensões, com o objetivo de travar o crescimento do número de beneficiários, devido ao processo, porventura demasiado flexível, de alargamento da cobertura dos esquemas de proteção social (Carolo, 2015: 132-133).

Mais tarde, na década de 1990, iniciaram-se as medidas de contenção da despesa nos sistemas de pensões (Chuliá e Asensio, 2007), destacando-se as seguintes reformas:

Década de 1990

As primeiras medidas foram tomadas em 1993, para controlar o aumento da despesa, estava no poder o PSD (centro-direita) que detinha maioria absoluta. Assim, no domínio do acesso às pensões de velhice, foi aumentado o prazo de garantia de 10 para 15 anos, no cálculo das pensões, a taxa de formação da pensão diminuiu de $2,2 \%$ para $2 \%$, os salários passaram a ser revalorizados pelo índice preços no consumidor (IPC) e foi definida uma pensão mínima. Nessa pensão, à pensão estatutária foi acrescentado um "complemento social", definido como uma prestação não contributiva, a ser financiado por transferências do Orçamento de estado e, por fim, no financiamento, foi reduzida a taxa social única (TSU), de 35,5\% para 34,75\% (taxa atual), sendo definida como compensação a consignação adicional de 1 ponto percentual do imposto sobre o valor acrescentado, designado "IVA social" (Mendes, 2005: 124-125), cujas receitas revertem para a segurança social.

Em 1995, já com o governo do PS (centro-esquerda), com maioria relativa, foi criada a Comissão do Livro Branco para a reforma da segurança social. Esta comissão reuniu um conjunto de especialistas e produziu um relatório com uma análise pormenorizada sobre a evolução e lacunas do sistema e respetivas recomendações para a sua reforma. Outro aspeto muito relevante levantado por esta comissão foi a denúncia do aproveitamento do estado no financiamento do sistema, referindo o não cumprimento do previsto na Lei de Bases de 1984, que estabelecia que as despesas com os regimes não contributivos, ação social e administrativas, fossem financiadas pelo Orçamento de estado e não pelo fundo previdencial (Carolo 2015: 114).

Ainda em 1999, na sequência de iniciativas pontuais em curso desde o final dos anos 80 , há que destacar a introdução de vários mecanismos de incentivo à 
reforma antecipada, motivados pelo objetivo de estímulo à criação de emprego, sobretudo para as camadas da população mais jovem, esperando ao mesmo tempo uma maior qualificação dos recursos humanos e consequente aumento da produtividade do fator trabalho.

\section{Reforma de 2000}

Em 2000, no segundo governo do Partido Socialista, também com maioria relativa, é realizada a primeira reforma da segurança social, que resultara de um processo alargado de análise técnica e discussão de medidas com vista ao reforço da sustentabilidade do sistema, nomeadamente através da criação da Comissão do Livro Branco da Reforma da Segurança Social em 1997. Contudo, por decisão política, esta reforma acaba por deixar de lado parte substancial das recomendações da comissão. Assim, a reforma acabou por se limitar à introdução de alterações na forma de cálculo das pensões, alargando gradualmente o período considerado, no sentido de ter em conta a média da carreira, que até então era a média dos melhores 10 anos de contribuições, prevendo porém um período de transição até à plena aplicação das novas regras, justificada com a necessidade de salvaguardar os direitos adquiridos mas também os direitos em formação. Neste pressuposto, legalmente (e não necessariamente constitucionalmente), qualquer governo estaria condicionado quanto à possibilidade de reforma no sistema de segurança social, atendendo à natureza do mecanismo do sistema de pensões, que assenta no pagamento diferido de um benefício. Daí a importância do princípio da confiança, conforme sustentado na decisão do TC em 2014, relativa ao corte nas pensões então proposto.

\section{Reforma de 2002}

No que se refere ao ordenamento jurídico do sistema de segurança social, em 2002, o tema de maior relevância foi a tentativa gorada de proceder ao plafonamento horizontal das contribuições para a segurança social. No fundo tratava-se de uma nova configuração dos princípios da segurança social assentes na partilha de responsabilidades, que na prática implicaria a introdução de um segundo pilar complementar de natureza privada, tal como havia sido proposto pelo novo governo de coligação entre o PSD e o CDS/PP saído das eleições de 2002.

Note-se que em termos institucionais esta teria sido a maior alteração ao sistema de pensões, pelo menos na arquitetura que advinha desde a reforma de 1962, e que no plano constitucional à partida nada impediria. Assim poder-se-á concluir que não foi pela CRP que não se fizeram reformas mais profundas no sistema.

Todavia, ainda nesta reforma, outro aspeto a considerar é a alteração da fórmula de cálculo das pensões. Mais uma vez, a reforma foi além da Constituição, ao introduzir o conceito de redistribuição do tipo de solidariedade intrageracional no sistema de pensões previdencial (Carolo, 2015: 110), através da nova fórmula de cálculo das pensões com taxas de formação regressivas, valorizando assim em termos relativos as contribuições dos salários mais baixos, prevista na reforma de 
2000 (PS) mas só regulamentada em 2002 e que viria a merecer concordância do novo governo, sem prejuízo de fazer aprovar uma nova Lei de Bases (PSD-CDS).

Reforma de 2007

O contexto económico subjacente à reforma de 2007 foi marcado pela necessidade de controlo orçamental, a par de um período de fraco crescimento económico, contrastante com toda a década de 1990, em que as consequências da adesão ao euro não serão irrelevantes. Acresce que, à época, as projeções da Comissão Europeia lançaram o alarme sobre os efeitos do envelhecimento no crescimento da despesa social, enquanto o governo se debatia com o efeito maturação ao nível do crescimento do número de pensionistas, principalmente na CGA. Perante duas reformas (2000 e 2002) que assumidamente não lograram atingir as mudanças que se propunham, o governo do Partido Socialista, investido da sua primeira maioria absoluta, teve assim a oportunidade para uma reforma sem restrições negociais nem necessidade de concertação. As principais medidas introduzidas foram:

- aceleração da convergência com fórmula de cálculo introduzida em 2002, de modo a considerar toda a carreira contributiva, sem prejuízo dos direitos adquiridos mas com prejuízo dos direitos em formação (componente da pensão já formada vs. contribuições futuras), ou seja, implicações significativas na taxa de substituição da pensão futura;

- introdução do fator de sustentabilidade (FS) indexado à evolução do indicador esperança média de vida publicado pelo INE;

- novas regras de indexação das pensões, e novo referencial em substituição do salário mínimo, o IAS;

- aplicação das novas medidas à CGA, incluindo o fator de sustentabilidade, acelerando assim o processo de convergência daquele regime com o RGSS.

Sistematizando, no sentido de se procurar uma perspetiva global das reformas, poder-se-ia considerar que houve três fatores principais que concorrem para explicar a evolução do sistema de proteção social em Portugal: (i) a nova Constituição, fruto do processo revolucionário conducente à transição democrática, que levou à consagração dos direitos sociais e respetivos ganhos de cobertura no sistema no sentido de colmatar as principais lacunas preexistentes; (ii) a integração europeia e o efeito da análise comparada dos indicadores sociais, com impactos positivos inequívocos tanto nas prioridades como na difusão de boas práticas na formulação das políticas sociais; (iii) e a maturação do sistema que coincidiu com uma conjuntura de austeridade, seguida de uma intervenção externa (PAEF).

Evidentemente, estes fatores, tendo estado sempre presentes, acabaram por ter preponderâncias diferentes na determinação dos resultados em termos de reformas no sistema de proteção social.

Para além da Constituição, a europeização foi sem dúvida mais importante na expansão do sistema (Pereirinha e Nunes, 2006) sobretudo nas inovações introduzidas, por exemplo, com a criação do RMG/RSI (1996-2002), do que a fase inicial 
de desenvolvimento democrático (1976-1985) em que se procurava "completar" a universalização do sistema de segurança social, tanto em termos de população coberta (cobertura pessoal) como de prestações sociais (cobertura material).

Mas esta mesma influência externa, que durante um longo período foi vista como um constrangimento positivo, ao conferir incentivos à expansão do sistema, foi sendo reconfigurada, sendo também, designadamente após a aplicação do PAEF, um constrangimento negativo, ao promover a retração do sistema. Ainda assim, também neste caso, a Europa funcionou como um recurso externo que tornou possível ao governo nacional levar a cabo reformas que desejava implementar mas que de outra forma não teria sido capaz. Desta feita, de sentido restritivo. Ou seja, após a crise financeira, assistimos a um regresso do papel da Europa enquanto instrumento de reforço da capacidade política e institucional do governo português, agora com novos contornos. Se bem que o MdE não previsse alterações significativas nas áreas sociais, as necessidades de ajustamento orçamental que se foram agudizando, levaram o governo a intervir nos grandes agregados de despesa, nomeadamente nas pensões. Esta decisão coexistiu com um redesenhar da rede de mínimos sociais, tornando o acesso às prestações baseadas em direitos de cidadania mais restritivo, enquanto se reforçavam as transferências para o $3 .^{\circ}$ setor e uma lógica assistencialista (Silva e Pereira, 2016).

Todavia, ao longo do período analisado, houve também outros efeitos positivos, nomeadamente ao nível da eficácia no combate à pobreza e da promoção de maior equidade na distribuição de rendimento. Eis alguns casos exemplares:

1996 - Criação do RMG como reconhecimento do direito ao rendimento (ainda que mínimo) como condição de cidadania (e não reconhecimento de necessidade feito pelos serviços, numa lógica assistencialista, o que não significa que não persista ainda uma certa subjetividade no processo de decisão e até a cultura assistencialista por parte dos técnicos e de algumas normas).

2000-2002-2005 - Aumento das pensões mínimas/CSI - decorrente da evidência dos elevados índices de pobreza entre os pensionistas e trabalhadores em contraste com a realidade europeia (Costa et al., 2008), reforçando assim o papel dos mínimos sociais no assegurar de um rendimento digno assente na condição de cidadania.

2002-2007 - Enfoque na redistribuição de rendimento nas reformas operadas na segurança social, ou pelo menos na necessidade de eliminar regressividades associadas a algumas prestações sociais, sobretudo ao nível da fórmula de cálculo das pensões e subsídio de desemprego.

2011-2014, PAEF - Apesar dos efeitos agregados negativos que as medidas tomadas neste período tiveram no rendimento dos agregados familiares, os cortes nas pensões incorporaram preocupações de progressividade. Contudo, e em contraste, os cortes em prestações sociais, como o RSI, o CSI ou o abono de família, tiveram um impacto claramente regressivo, atingindo os primeiros decis da distribuição de rendimentos, contribuindo para o agravamento da pobreza e das desigualdades. 
Do mesmo modo, ao olharmos para as reformas no sistema de pensões, verificamos que estas foram motivadas, não exclusiva mas principalmente, por razões de controlo da despesa - assentando, por vezes, em medidas contra a CRP, como foi o caso da introdução da CES (Silva, Joaquim e Pereira, 2015).

Seguindo este pressuposto, a única reforma de natureza restritiva que poderia ser entendida como seguindo um princípio constitucional de um regime de segurança social unificado seria o encerramento da CGA para novos subscritores (2005) e a respetiva aceleração da convergência prevista, em resultado da reforma de 2007, ainda que salvaguardando os direitos adquiridos pela consideração de duas parcelas da pensão (P1 e P2) na aplicação das novas regras de cálculo, com exceção do fator de sustentabilidade, que se aplicou a todos os novos pensionistas logo em 2008, bem como a legislação subsequente em 2009, que determinaria a aplicação das mesmas regras entre CGA e RGSS. Note-se que esta foi talvez a primeira vez que se aplicou uma regra, neste caso o FS, simultaneamente, aos dois subsistemas (CGA e RGSS). No plano constitucional, com base na premissa de que a reforma de 2007 e as medidas nela introduzidas foram, ainda que de forma implícita, a derradeira reforma da CGA com vista à convergência total com o regime de segurança social (Carolo, 2015), é possível argumentar que, após esta reforma, o sistema de pensões em Portugal está mais próximo do preceito constitucional de um sistema de segurança social unificado que deve ser providenciado pelo estado (artigo 63. 으, n.. ${ }^{2}$, CRP 1976).

Já no que concerne o período de intervenção externa (PAEF) apesar das inúmeras medidas introduzidas (Silva, Joaquim e Pereira, 2015), estas seguiram o modelo de cortes generalizados, tanto nos salários como nas pensões, diferenciados em função dos níveis de rendimento, numa lógica de puro cost-containment, nalguns casos devidamente sancionados pelo Tribunal Constitucional, sem todavia ter sido introduzida ou sequer tentada qualquer reforma estrutural, porventura porque com o alcance tanto da reforma da segurança social de 2007 como da aceleração da convergência da CGA, muito pouca margem restava para que tal fosse possível, ao ponto de o memorando de entendimento nem sequer prever qualquer corte ou reforma no sistema de pensões.

\section{Maturação e convergência}

As quatro décadas de democracia traduziram-se numa enorme expansão da cobertura e da generosidade do sistema de proteção social português. A combinação de garantia de novos direitos e novas prestações sociais com o processo de maturação do sistema - fruto de transformações positivas no mercado de trabalho, nomeadamente ganhos salariais e de produtividade - provocou um aumento da despesa social, com notáveis benefícios de eficácia, qualquer que seja o indicador que consideremos.

Se a maturação do sistema é uma característica distintiva da democracia, outra, não menos marcante, é a convergência com os parceiros europeus. As políticas de proteção social portuguesas europeizaram-se, quer incorporando princípios 
organizadores promovidos a partir da Europa social, quer mimetizando soluções inovadoras desenvolvidas por outros estados-membros (Guillén, Álvarez e Silva, 2005; Silva, 2011).

A proteção social foi, por isso, uma área de profunda transformação institucional, política e económica. Com a transição para a democracia, a arquitetura do estado social português alterou-se muito, com implicações materiais de grande alcance. A figura 1 dá conta disso mesmo. Independentemente do risco considerado, assistiu-se a um crescimento significativo do número de beneficiários de prestações sociais. Em 40 anos, o número de pensões pagas duplicou (situa-se hoje em redor dos 3 milhões); o de beneficiários de proteção no desemprego - muito sensível ao ciclo económico - passou de números residuais para um valor em redor do meio milhão; e a rede de mínimos sociais, que se podia caraterizar como sendo praticamente inexistente aquando da transição para a democracia, protege hoje, considerando apenas as prestações diferenciais, com exigentes condições de recursos (isto é, o rendimento social de inserção e o complemento solidário para idosos), perto de 500 mil portugueses. Da mesma forma, a rede de serviços à família, assente numa contratualização entre o estado e o $3 .^{\circ}$ setor, tem níveis de cobertura que não podem ser comparados com os preexistentes.

No essencial, esta maturação do sistema dependeu de transformações positivas de natureza económica e demográfica, mais do que de decisões políticas dos sucessivos governos, em particular ao longo das últimas duas décadas. Com efeito, desde o início da década de 1990, analisado o conjunto das opções governativas na área da proteção social - e pese embora a garantia de novos direitos, designadamente na área da solidariedade -, as escolhas políticas foram de natureza restritiva, procurando conter o crescimento da despesa (em particular no regime previdencial, que representa, como é sabido, o grosso da despesa com proteção social) (Silva e Pereira, 2015).

Não obstante a forte expansão da proteção social em Portugal nas últimas quatro décadas - quer a nível dos riscos cobertos, quer ao nível dos beneficiários abrangidos - , a evolução da despesa social pública em proporção da riqueza produzida segue uma trajetória convergente com os patamares de despesa de grande parte dos países europeus (figura 3). Portugal percorreu, com atraso, o caminho que muitos países tinham iniciado 30 anos antes, logo após o pós-guerra, e com particular intensidade na década de 60 . Este caminho permitiu a criação e consolidação do estado social, tal como o conhecemos hoje, e a aproximação dos padrões de desenvolvimento aos das restantes democracias europeias.

A maturação do estado social reflete-se não apenas na expansão da despesa como na alteração da sua composição (figura 4). Neste domínio, destaca-se o aumento do peso relativo da despesa com proteção no desemprego - que reflete também, mas não apenas, a subida da taxa de desemprego ao longo do tempo - , a redução do peso das prestações de apoio à família, doença e maternidade e um aumento moderado do peso da despesa com pensões em virtude do crescimento do número de pensionistas e de uma evolução no sentido de carreiras contributivas mais longas e completas. Refere-se ainda, a este nível, a expansão da despesa com outras prestações sociais, em particular ao longo das últimas duas décadas, em 


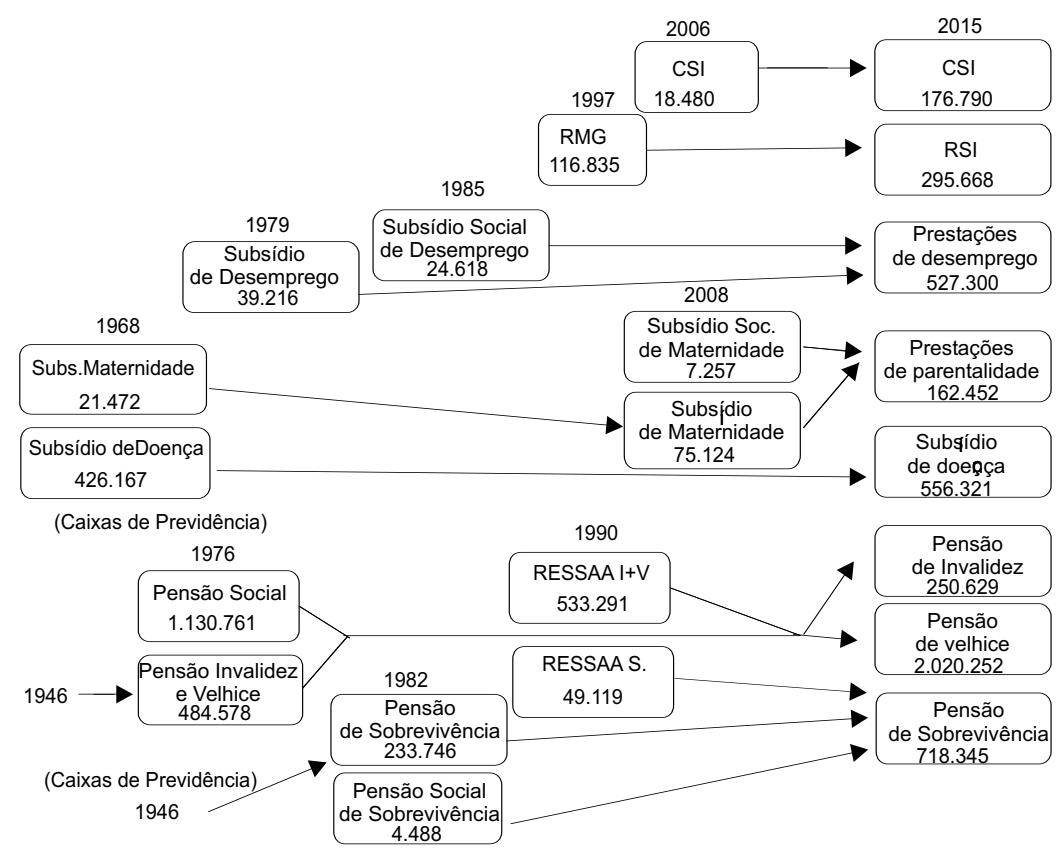

Figura 1 Maturação do sistema de segurança social português

Fonte: Adaptado de "Estatísticas da Segurança Social" - GEP-MTSSS.

Quadro 1 Número médio de anos de carreira contributiva dos novos pensionistas do regime geral da segurança social — pensões de velhice

\begin{tabular}{cccccccccc}
\hline Ano & 2001 & 2005 & 2010 & 2014 & $2020^{*}$ & $2030^{*}$ & $2040^{*}$ & $2050^{*}$ & $2060^{*}$ \\
\hline $\begin{array}{c}\text { Número médio de } \\
\text { anos de contribuições }\end{array}$ & 20,6 & 23,4 & 25,5 & 26,5 & 31 & 32,4 & 33,1 & 34,6 & 36,4 \\
\hline
\end{tabular}

Fonte: IGFSS: Conta da Segurança Social 2002, Conta da Segurança Social 2014; Comissão Europeia: "The 2015 Ageing Report"*.

parte explicado pelo desenvolvimento de uma rede de mínimos sociais destinada ao alívio da pobreza e da exclusão social.

O processo de maturação e consolidação do estado social teve impacto na elevação das condições de vida da população como um todo, mas reflete-se de forma particularmente expressiva na melhoria da situação das famílias de mais baixos rendimentos. O grau de eficácia das transferências sociais na redução da pobreza mede-se pelo diferencial da taxa de pobreza antes e após transferências sociais (quadro 2). Os últimos dados disponíveis (2014) apontam para um efeito de redução da pobreza através das transferências sociais de cerca de 28,3 p.p. 


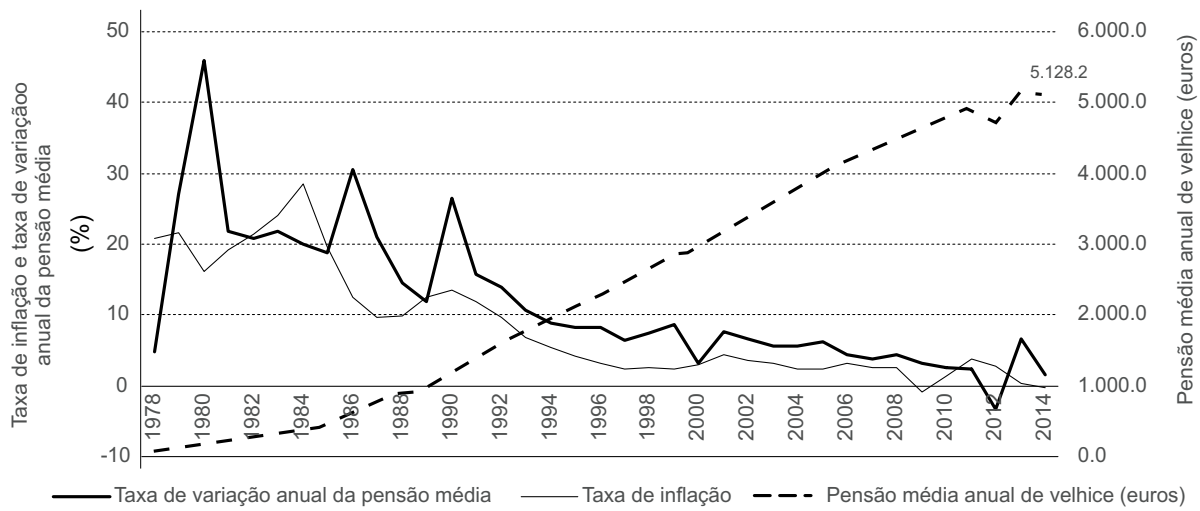

Figura 2 Evolução da pensão média anual de velhice (segurança social)

Fonte: Pordata e cálculos próprios.

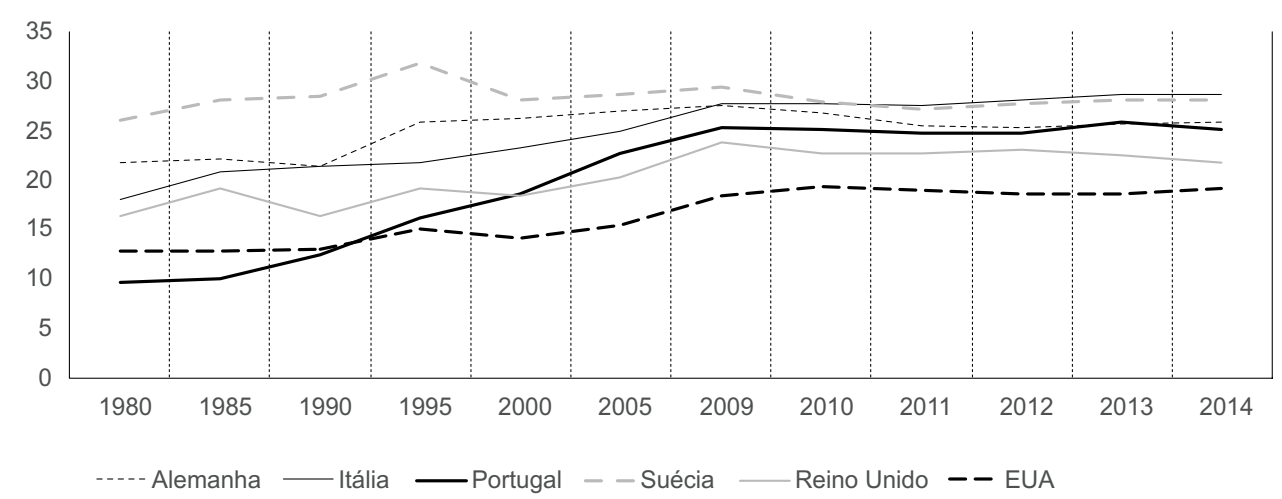

Figura 3 Despesa pública em proteção social em \% do PIB Fonte: OCDE.

Esta evolução beneficiou particularmente a população idosa, grande parte da qual com pensões muito baixas ou inexistentes, fruto do efeito combinado de fracas carreiras contributivas com baixos salários. Só nas últimas duas décadas a taxa de pobreza entre os idosos diminuiu em cerca de 23 p.p., por força dos aumentos dos complementos sociais para as pensões. A desigualdade na distribuição de rendimentos, medida pelo índice de Gini, tem também apresentado uma evolução decrescente, mas de mais fraca intensidade, situando Portugal ainda muito aquém dos patamares médios europeus observados para este indicador. 


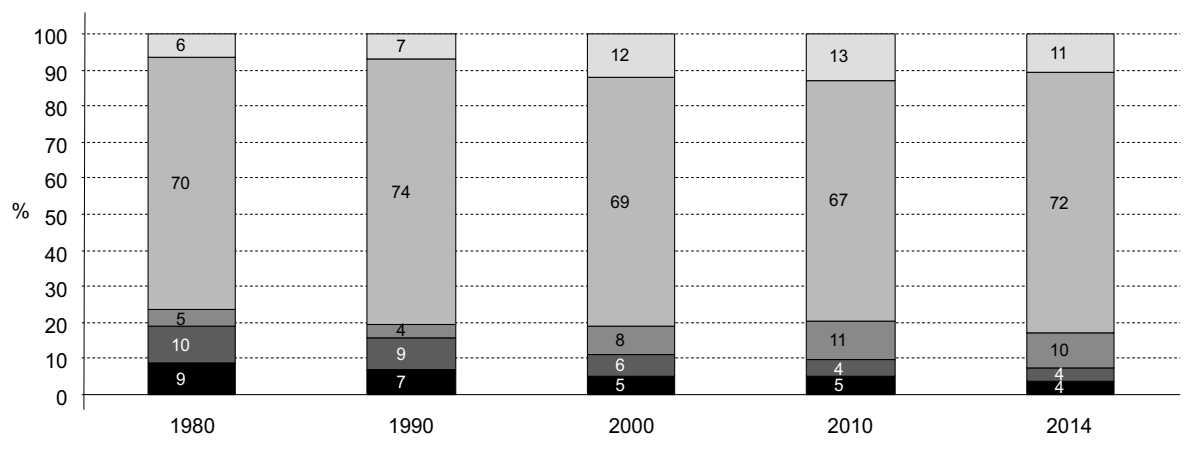

- Familiares $\square$ Doença e maternidade $\square$ Desemprego e apoio ao emprego $\square$ Pensões, suplementos e complementos $\square$ Outras

Figura 4 Composição da despesa da segurança social com prestações sociais por principais agregados

Quadro 2 Evolução dos indicadores de risco de pobreza e desigualdades de rendimento (1995-2014)

\begin{tabular}{|c|c|c|c|c|c|c|}
\hline & 1995 & 2000 & 2005 & 2010 & 2014 & $\begin{array}{l}\text { Var } \\
1995-2014\end{array}$ \\
\hline $\begin{array}{l}\text { Taxa de risco de pobreza antes } \\
\text { de transferências sociais }\end{array}$ & 37,0 & 37,0 & 40,2 & 42,5 & 47,8 & $+10,8 p p$ \\
\hline $\begin{array}{l}\text { Taxa de risco de pobreza após } \\
\text { transferências sociais }\end{array}$ & 21,0 & 20,0 & 18,5 & 18,0 & 19,5 & $-1,5 p p$ \\
\hline $\begin{array}{l}\text { Taxa de risco de pobreza entre os idosos } \\
\text { ( } 65 \text { ou mais anos) }\end{array}$ & 38,0 & 33,0 & 27,6 & 21,0 & 15,1 & $-22,9 p p$ \\
\hline Îndice de Gini & 36,0 & 37,0 & 37,7 & 34,2 & 34,0 & $-2 p p$ \\
\hline
\end{tabular}

Fonte: Eurostat, Pordata.

Uma das singularidades do estado social português é a forma como estado e 3. - setor se articulam para garantir respostas sociais. Aliás, esta é uma matéria onde a margem de manobra oferecida pela Constituição foi sendo utilizada para reforçar este pacto social.

Não obstante, em termos globais, Portugal se caraterizar por baixos níveis de participação em organizações da sociedade civil, no contexto europeu, o peso da sociedade civil organizada em torno de respostas sociais tem grande expressão. Esta singularidade emerge de um contexto de evolução histórica particular. Se antes do 25 de Abril de 1974 o estado assumia um papel supletivo na proteção social, e os apoios à família e de alívio da pobreza recaíam, sobretudo, sobre as mutualidades, as misericórdias e as, hoje denominadas, instituições particulares de solidariedade social (IPSS), com a transição para a democracia, a par do forte 


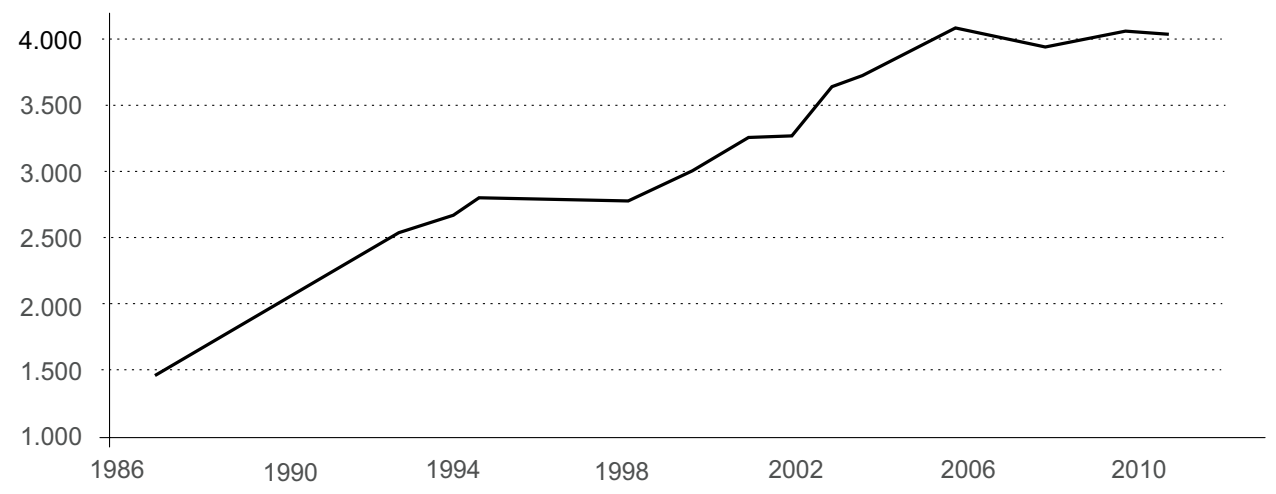

Figura 5 Evolução do número de instituições particulares de solidariedade social sem fins lucrativos Fonte: Joaquim (2015).
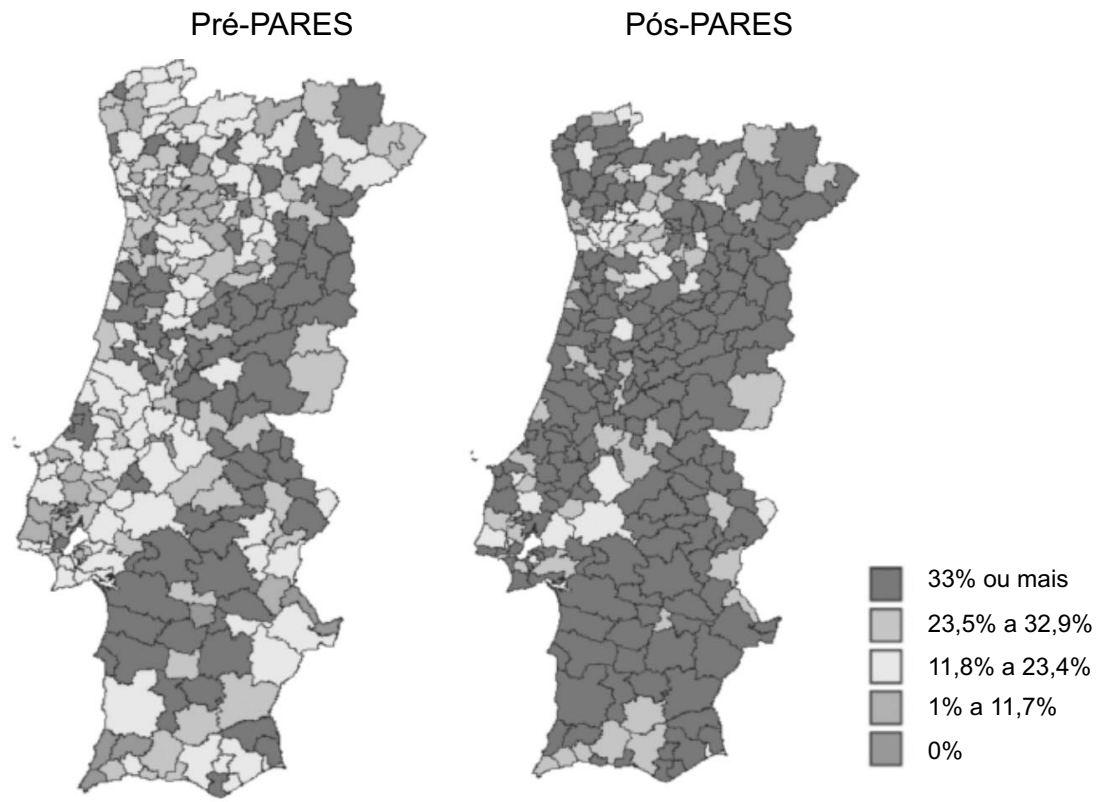

Figura 6 Cobertura nacional (Portugal continental) da resposta social "creche" Fonte: Joaquim (2015) 
desenvolvimento do estado social português, assistiu-se a um crescimento significativo das IPSS (figura 5). A mesma evolução não se verificou ao nível das mutualidades e misericórdias, que cresceram marginalmente em virtude de cobrirem áreas de proteção que o estado passou a definir como direitos universais assegurando o seu financiamento, gestão e provisão.

Nas décadas de 1970 e 1980 a parceria entre o estado e as IPSS foi-se consolidando. A partir dos anos 80, em particular, o número de IPSS cresce exponencialmente e desenvolve-se uma vasta rede de equipamentos sociais - lares, creches, centros de dia, cantinas sociais -, investimento em parte alavancado por fundos comunitários. Foi esta parceria entre o estado e as IPSS, materializada no Pacto de Cooperação em 1996 e, mais tarde, em 2006, com o programa PARES, que garantiu uma forte expansão da cobertura territorial destes equipamentos e, em particular, das creches (figura 6). Esta articulação de respostas coloca, no entanto, questões importantes quanto à capacidade de o estado regular a atividade destas instituições, financiadas com recursos públicos, assim como garantir que o princípio da igualdade de oportunidades é assegurado.

\section{Considerações finais}

Ao longo deste texto, procurámos demonstrar como a Constituição portuguesa apresenta na área da proteção social um conjunto de singularidades, quando comparada com outras áreas sociais. Enquanto na saúde e na educação, à transição para a democracia correspondeu uma reorientação profunda do sistema, o mesmo já não é verdade quando pensamos na proteção social. Neste domínio, o sistema manteve a sua natureza bismarckiana, se bem que esta tenha passado a coexistir com um alargamento muito significativo da proteção, quer quanto aos riscos cobertos, quer quanto à sua intensidade. Se bem que, no sistema previdencial, a matriz ocupacional tenha prevalecido, esta articula-se com uma rede de mínimos e de combate à pobreza de natureza beveridgeana, fundada em direitos universais de cidadania.

Durante a democracia portuguesa, com a modernização da economia portuguesa e os ganhos salariais e de emprego, assistiu-se a um processo de acelerada maturação do estado social português, com evidentes ganhos de eficácia - visíveis, nomeadamente na diminuição da pobreza e da sua severidade. Concomitantemente, primeiro com o período de transição que se seguiu ao 25 de Abril, e, uma década depois, com a adesão à União Europeia, o sistema de proteção social português beneficiou de um movimento de modernização, visível na criação de novos direitos e, igualmente importante, em novos princípios orientadores das políticas.

Em todo o caso, se bem que a Constituição tenha um conjunto de disposições relevantes em matéria de proteção social - que, de facto, circunscrevem a margem política de que gozaram os sucessivos governos -, não é menos verdade que, ao longo de quatro décadas, os governos aplicaram medidas programaticamente distintas e implementaram estratégias reformistas diferenciadas (quer no sentido dado às reformas - mais ou menos restritivas ou expansionistas -, quer, aspeto 
particularmente marcante, na divisão de responsabilidades entre estado, poder local e 3.. setor).

Outra dimensão importante para a governação na área da proteção social - e que assumiu grande visibilidade no período recente, de aplicação do PAEF - remete para a proteção constitucional dos direitos sociais. Tendo em conta a natureza ocupacional do sistema previdencial, que está explícita no texto constitucional, naturalmente que as prestações sociais assentes no seguro social gozam de um grau de proteção constitucional muito significativo. Os sucessivos acórdãos do Tribunal Constitucional durante a aplicação do MdE vão, aliás, nesse sentido. Contudo, a jurisprudência do Tribunal Constitucional vai também no sentido de proteger o direito de todos os cidadãos a um nível mínimo de recursos materiais, dando, assim, proteção à rede de mínimos entretanto constituída.

Neste sentido, podemos afirmar que a trajetória de maturação e convergência do sistema de proteção social português é consequência, por um lado, de um conjunto de transformações económicas, sociais e demográficas ocorridas na nossa sociedade e, por outro, de um processo político, no qual a afirmação programática dos governos foi relevante, mas em que a europeização e o texto constitucional desempenharam papéis igualmente determinantes. Europa e Constituição foram fundamentais ao darem incentivos concretos para o desenvolvimento de soluções com configurações específicas, mas também ao restringirem a margem de manobra política dos governos.

Hoje, o estado social português, à imagem do que sucede no espaço europeu, está confrontado com um conjunto articulado de desafios. Por um lado, o da sustentabilidade e da adequação; por outro, garantir a igualdade ao longo do ciclo de vida e entre grupos sociais.

Da mesma forma que nas últimas quatro décadas a Constituição foi instrumental ao enformar as opções políticas, dando autonomia ao poder político, mas, também, circunscrevendo o espaço discricionário para a sua ação, o seu papel será também fundamental no futuro.

Nesta perspetiva, há um conjunto de questões que se colocam:

- Sobre a redistribuição ao longo do ciclo de vida: tendo em conta a evolução projetada das taxas de substituição decorrentes das alterações à fórmula de cálculo das pensões (reformas de 2002 e 2007), bem como o aumento da longevidade, como é que será possível garantir um nível adequado de pensões de velhice para os futuros pensionistas, equilibrando preocupações de sustentabilidade, equidade intergeracional e atendendo às expectativas legitimas dos atuais contribuintes?

- Sobre a sustentabilidade financeira: quais são as condições para alargar a base de financiamento do regime previdencial, diversificando as fontes e preservando os princípios do seguro social, aliás não só constitucionalmente consagrados como tendo sido reforçados pela jurisprudência do Tribunal Constitucional?

- Qual a margem para expandir a rede de mínimos sociais, assente na condição de recursos e em prestações diferenciais, e de que forma esta expansão obriga 
a repensar a organização dos complementos sociais, assim como a própria pensão social?

- De que forma deve evoluir a relação entre estado e $3 .^{\circ}$ setor na promoção de respostas sociais, designadamente nos serviços prestados à família, e que tipo de contratualização do financiamento e de regulação pública deve ser desenvolvido?

\section{Referências bibliográficas}

Assembleia Constituinte (1976), Constituição da República Portuguesa, disponível em: http://www.cne.pt/sites/default/files/dl/crp_1976.pdf (última consulta a 07/09/2016).

Assembleia da República (1982), Lei Constitucional n.. 1/82, disponível em: http://www.cne.pt/sites/default/files/dl/crp_1982.pdf (última consulta a 07/09/2016).

Assembleia da República (1987), Lei Constitucional n.ำ 1/89, disponível em: http://www.cne.pt/sites/default/files/dl/crp_1989.pdf (última consulta a 07/09/2016).

Assembleia da República (1992), Lei Constitucional n..$^{\circ}$ 1/92, disponível em: http://www.cne.pt/sites/default/files/dl/crp_1992.pdf (última consulta a 07/09/2016).

Assembleia da República (1997), Lei Constitucional n.ำ 1/97, disponível em: http://www.cne.pt/sites/default/files/dl/crp_1997.pdf (última consulta a 07/09/2016).

Assembleia da República (2001), Lei Constitucional n.ํ 1/2001, disponível em: http://www.cne.pt/sites/default/files/dl/crp_2001.pdf (última consulta a 07/09/2016).

Assembleia da República (2004), Lei Constitucional n. ${ }^{\circ}$ 1/2004, disponível em: http://www.cne.pt/sites/default/files/dl/crp_2004.pdf (última consulta a 07/09/2016).

Assembleia da República (2005), Lei Constitucional n. ${ }^{\circ}$ 1/2005, disponível em: http://www.cne.pt/sites/default/files/dl/crp_2005.pdf (última consulta a 07/09/2016).

Branco, F. (2001), A Face Lunar dos Direitos Sociais. Virtualidades e Limites do RMG como Direito de Cidadania em Portugal, São Paulo, Pontifícia Universidade Católica de São Paulo, tese de doutoramento em Serviço Social.

Carolo, Daniel (2006), A Reforma da Previdência Social de 1962 na Institucionalização do Estado-Providência em Portugal, Lisboa, Instituto Superior de Economia e Gestão da Universidade de Lisboa, dissertação de mestrado.

Carolo, D. (2015), Despesa e Redistribuição na Segurança Social em Portugal. Análise da Reforma de 2007, Lisboa, Instituto de Ciências Sociais da Universidade de Lisboa, tese de doutoramento em Ciências Sociais, especialidade de Sociologia Política.

Carolo, D., e J. A. Pereirinha (2010), “The development of the welfare State in Portugal: trends in social expenditure between 1938 and 2003", Revista de História Económica - Journal of Iberian and Latin American Economic History, 28 (3), Cambridge University Press, pp. 469-501. 
Carreira, H. M. (1996), “As políticas sociais em Portugal”, em António Barreto (org.), A Situação Social em Portugal, 1960-1995, Lisboa, Imprensa de Ciências Sociais.

Chuliá, E., e M. Asensio (2007), "Portugal: in search of a stable framework", em E. M. Immergut, K. M. Anderson e I. Schulze (orgs.), The Handbook of West European Pension Politics, Oxford, Oxford University Press.

Costa, Alfredo Bruto da (1986), “A despesa social pública em Portugal, 1960-1983", Planeamento, 1-2-3, pp. 7-67.

Costa, Alfredo Bruto da, Isabel Baptista, Pedro Perista, e Paulo Carrilho (2008), Um Olhar sobre a Pobreza. Vulnerabilidade e Exclusão Social no Portugal Contemporâneo, Lisboa, Gradiva.

Ferrera, Maurizio (1996), "The 'Southern Model' of welfare in social Europe", Journal of European Social Policy, 6 (1), pp. 17-37.

Guillén, A., S. Álvarez, e P. A. Silva (2005), “O redesenhar dos Estados-providência espanhol e português: o impacto da adesão à União Europeia", em Sebastián Royo (org.), Portugal, Espanha e a Integração Europeia. Um Balanço, Lisboa, Imprensa de Ciências Sociais.

Joaquim, C. (2015), "Proteção social, terceiro setor e equipamentos sociais: que modelo para Portugal?", Cadernos do Observatório sobre Crises e Alternativas, 3, CES-UC, pp. 5-71.

Lucena, M. (1976), A Evolução do Sistema Corporativo Português, vol. I: O Salazarismo, vol. II: O Marcelismo, Lisboa, Perspectivas e Realidades.

Lucena, M. (1982), “Transformações do Estado Português nas suas relações com a sociedade civil”, Análise Social, XVIII (72-73-74), pp. 897-926.

Maia, F. (1984), Segurança Social em Portugal. Evolução e Tendências, Madrid, Organización Iberoamericana de Seguridad Social.

Mendes, F. R. (2005), Conspiração Grisalha. Segurança Social, Competitividade e Gerações, Oeiras, Celta Editora.

Pereirinha, J. A., e F. Nunes (2006), “Política social em Portugal e a Europa, 20 anos depois", em António Romão (coord.), Economia Portuguesa. Vinte Anos Depois, Coimbra, Edições Almedina, pp. 283-326.

Silva, P. A. (2002), “O modelo de welfare da Europa do Sul: reflexões sobre a utilidade do conceito", Sociologia, Problemas e Práticas, 38, pp. 25-59.

Silva, P. A. (2011), “The Europeanisation of social policies in Portugal”, Portuguese Journal of Social Science, 10 (1), pp. 3-22.

Silva, P. A., e M. T. Pereira (2015), Cuidar do Futuro. Os Mitos sobre o Estado Social Português, Lisboa, Clube do Autor.

Silva, P. A., e M. T. Pereira (2016), “O Estado Social Português: entre a maturação e os constrangimentos externos", em Conceição Pequito Teixeira (coord.), Política Comparada. O Sistema Político Português Numa Perspetiva Comparada, Cascais, Principia.

Silva, P. A., C. Joaquim, e M. T. Pereira (2015), “O Programa de Assistência Económica e Financeira e as pensões”, em M. L. Rodrigues e P. A. Silva (orgs.), Governar com a Troika. Políticas Públicas em Tempo de Austeridade, Coimbra, Edições Almedina, pp. 317-344.

Tribunal Constitucional (2002), Acórdão n. ${ }^{\circ}$ 509/02, disponível em: http://www.pgdlisboa.pt/jurel/cst_busca_actc.php?ano_actc=2002\&numero_actc=5 09/02 (última consulta a 07/09/2016). 
Tribunal Constitucional (2013), Acórdão n.ํ 862/2013, disponível em:

http://www.pgdlisboa.pt/jurel/cst_busca_actc.php?ano_actc=2013\&numero_actc=8

62 (última consulta a 07/09/2016).

Ana Rita Ferreira. Professora auxiliar convidada de Ciência Política na

Universidade da Beira Interior, Covilhã, Portugal. E-mail: arita_ferreira@yahoo.com

Daniel Carolo. Research fellow do Institute of Public Policy Thomas

Jefferson-Correia da Serra e Coordenador-executivo do projecto Um Sistema de

Pensões para o Futuro, Lisboa, Portugal. E-mail: dcarolo@ipp-jcs.org

Mariana Trigo Pereira. Técnica especialista no Ministério do Trabalho, da

Solidariedade e da Segurança Social, Lisboa, Portugal.

E-mail: marianatp@gmail.com

Pedro Adão e Silva. Professor auxiliar convidado da Escola de Sociologia e

Políticas Públicas do Instituto Universitário de Lisboa (ISCTE-IUL), Av. das Forças

Armadas, 1649-025 Lisboa, Portugal. E-mail: padaoesilva@gmail.com 